\title{
THE IMPACT OF NITROGEN OXIDES EMISSIONS FROM AIRCRAFT UPON THE ATMOSPHERE AT FLIGHT ALTITUDES-RESULTS FROM THE AERONOX PROJECT
}

\author{
U. SCHUMANN \\ Deutsche Forschungsanstalt für Luft- und Raumfahrt (DLR), Institut für Physik der Atmosphäre, \\ Oberpfaffenhofen, 82230 Wessling, Germany
}

(First received 15 February 1996 and in final form 21 August 1996. Published March 1997)

\begin{abstract}
The AERONOX project investigated the emissions of nitrogen oxides $\left(\mathrm{NO}_{x}\right)$ from aircraft engines and global air traffic at cruising altitudes, the resultant increase in $\mathrm{NO}_{x}$ concentrations, and the effects on the composition of the atmosphere, in particular with respect to ozone formation in the upper troposphere and lower stratosphere. The project was structured into three subprojects: Engine exhaust emissions, physics and chemistry in the aircraft wake, and global atmospheric model simulations. A complementary program of work by aviation experts has provided detailed information on air traffic data which was combined with data on aircraft performance and emissions to produce a global emissions inventory. This summary gives an overview of the results of this project. Further details are given in the following papers of this issue and the final project report of 1995 .

The work resulted in improved predictive equations to determine $\mathrm{NO}_{x}$ emissions at cruise conditions based on available data for aircraft/engine combinations, and $\mathrm{NO}_{x}$ emission measurements on two engines in cruise conditions. This information was combined with a traffic database to provide a new global $\mathrm{NO}_{x}$ emissions inventory. It was found that only minor chemical changes occur during the vortex regime of the emission plume; however, this result does not exclude the possibility of further changes in the dispersion phase. A variety of global models was set up to investigate the changes in $\mathrm{NO}_{x}$ concentrations and photochemistry. Although aviation contributes only a small proportion (about $3 \%$ ) of the total global $\mathrm{NO}_{x}$ from all anthropogenic sources, the models show that aviation contributes a large fraction to the concentrations of NOX in the upper troposphere, in particular north of $30^{\circ} \mathrm{N}$. (C) 1997 Elsevier Science Ltd. All rights reserved.
\end{abstract}

Key word index: Engine exhausts, air traffic, ozone, plumes, chemical transport, global circulation.

\section{ACRONYMS AND ABBREVIATIONS}

$\begin{array}{ll}\text { AERONOX } & \begin{array}{l}\text { EU-project "The impact of } \mathrm{NO}_{x} \text { emissions } \\ \text { from aircraft upon the atmosphere at flight } \\ \text { altitudes 8-15 km" }\end{array} \\ \text { ANCAT } & \begin{array}{l}\text { Abatement of Nuisances Caused by Air } \\ \text { Transport, a technical committee of the }\end{array} \\ \text { ECAC } & \begin{array}{l}\text { European Commission } \\ \text { ECAC }\end{array} \\ \text { ICAO } & \begin{array}{l}\text { European Civil Aviation Conference } \\ \text { International Civil Aviation Organisation } \\ \text { NASA }\end{array} \\ \text { National Aeronautics and Space Adminis- } \\ \text { tration }\end{array}$

\section{INTRODUCTION}

Emissions from aircraft engines include carbon dioxide $\left(\mathrm{CO}_{2}\right)$, water vapour $\left(\mathrm{H}_{2} \mathrm{O}\right)$, nitrogen oxides $\left(\mathrm{NO}_{x}=\mathrm{NO}+\mathrm{NO}_{2}\right)$, various sulphur oxides $\left(\mathrm{SO}_{x}\right)$, carbon monoxide $(\mathrm{CO})$, various non-methane hydrocarbons (NMHC), and other gases and particles. Such emissions from global subsonic air traffic may contribute to anthropogenic climate changes by increasing ozone and cloudiness in the upper troposphere, and by enhancing the greenhouse effect (Schumann, 1994). At present, the exhaust emissions from aircraft are small compared to anthropogenic surface emissions. Nearly $6 \%$ of all petrol products are burned as aviation fuel. Relative to the total anthropogenic emissions of carbon dioxide, aviation contributes about $2.6 \%$. With respect to $\mathrm{NO}_{x}$ the contributions from aviation amount to about $3 \%$ of all anthropogenic sources. Nevertheless, the unique location of aircraft emissions in the upper atmosphere and the predicted growth of air traffic demand require that particular attention is given to the effects of these emissions.

At cruise altitude, the greenhouse effect of emitted water and of additional ozone (due to emissions of nitrogen oxides) is potentially large compared to that caused by the same emissions near the Earth surface. This is because of relatively larger residence times at flight altitudes, low background concentrations, low temperature, and large radiative efficiency (Brühl and Crutzen, 1988; Johnson et al., 1992; Beck et al., 1992; Mohnen et al., 1993; Fortuin et al., 1995; WMO, 
1995). Air traffic is increasing globally by about $5-6 \%$ per year, and fuel consumption by about $3 \%$. The relative importance of these growth rates depends on the growth rates of other anthropogenic emissions. The climatic changes due to air traffic may enhance other environmental problems originating, e.g. from anthropogenic carbon dioxide or methane emissions. Hence, air-traffic-induced emissions are of growing importance.

Subsonic air traffic is thought to affect the present state of the atmosphere mainly by its emissions of $\mathrm{NO}_{x}$ at high altitudes. Over the North Atlantic, about $40 \%$ of all aviation fuel (on an annual mean basis) is burned by aircraft flying above the tropopause (Hoinka et al., 1993), i.e. in the lower stratosphere, the remainder being consumed in the upper troposphere. The zonally averaged mean concentration increase of $\mathrm{NO}_{x}$ in the upper troposphere due to aircraft emissions is expected to be of the order of $30 \%$ (Ehhalt et al., 1992), but more than $100 \%$ over regions with heavy traffic such as Europe, the USA and in the Northern Atlantic flight corridor (Schumann, 1994). Models predict that these increases, in turn, cause an increase of around $10 \%$ to ozone in the upper troposphere (e.g. Beck et al., 1992). It has been suggested that present air traffic may have caused a major part of the observed ozone increase (Fehsenfeld and Liu, 1994; Schumann, 1994) in the upper troposphere. However, ozonesonde observations suggest trends in tropospheric ozone increases (Logan, 1994) which are not fully correlated with the trends in aviation emissions. Hence, the quantitative effects of aviation on tropospheric ozone have not yet been observed from climatological data.

Until fairly recently, the environmental effects resulting from aircraft exhaust emissions were a minor item in the general debate on the environment. However, the growing awareness on global climate changes has brought about a discussion, especially in Europe and North America, and aircraft emissions are now perceived as a far more relevant issue than a decade ago (Schumann and Wurzel, 1994). In the early 1970 s, the potential effects of emissions from a proposed fleet of supersonic transports (Harrison, 1970; Johnston, 1971; Crutzen, 1971, 1972) were investigated in an extensive study (CIAP, 1975). Several independent assessments were also carried out in Europe (COMESA, 1976; COVOS, 1976). Economical reasons prevailed when it was decided at that time that such a fleet of SST (supersonic transport) aircraft should not be built in the U.S.A. Recently, there has been renewed interest in the development of faster aircraft for international passenger flight, both in the U.S.A. (NRC, 1994), Europe (ANAE, 1994; EAC, 1995), and other countries. The question how far such a system is environmentally acceptable with respect to ozone, climate, noise, fuel consumption and other questions triggered the High-Speed Research Program by NASA in 1990 (Stolarski and Wesoky, 1993; NRC, 1994; Thompson et al., 1996).
Relatively few studies have addressed specifically the impact of subsonic aircraft on the environment, and most previous investigations concentrated on aircraft noise and regional pollution effects near major airports. In 1987, a meeting at the Evangelische Akademie Tutzing in Germany, see Held (1990), initiated an intense discussion, at least national, on the impact of global air traffic, which has become a major topic of parliamentary discussions; see e.g. Deutscher Bundestag (1994). In view of the rapid growth of air traffic and the growing awareness of global climate changes, the discussion has become worldwide.

The civil aircraft industry also has a keen interest in ensuring that its products are environmentally acceptable. It is looking to a future, where a doubling of air traffic is expected to occur within the next 10 to 20 years causing an increasing demand for new aircraft. New technologies may be developed to reduce the specific fuel consumption and the $\mathrm{NO}_{x}$ emissions while keeping the aircraft technically sound, safe and economical. In view of the long development times and high investment requirement for new technologies, industry and regulators need early information on the expected impact of future aviation and required regulations. Therefore, the aviation industry has an existential interest in learning about the emissions impact on the atmosphere and supports related thorough research.

In 1990, an international Colloquium provided an overview on the state of knowledge with respect to the impact of global air traffic on the atmosphere (Schumann, 1990). It appeared from the beginning that aviation causes neither dominant nor negligible effects on the atmosphere, but there were few more definite statements. Hence, at that time, the state of knowledge was far too incomplete for conclusive assessments of the impact of aviation on the environment.

Therefore, the AERONOX project was set up to determine the emissions of $\mathrm{NO}_{x}$ from aircraft engines and global air traffic at cruising altitudes, the resultant increase in $\mathrm{NO}_{x}$ concentrations, and the effects on the composition of the atmosphere. The project addressed the following questions: (1) What are the aircraft engine emissions throughout the entire flight cycle? (2) What is the chemical composition in the wake of aircraft when it reaches the grid size of the atmospheric models? (3) How are $\mathrm{NO}_{x}$ emissions distributed from the aircraft to the global scale, what are the resultant concentration increases, and what are the consequences of these emissions with respect to the photochemistry of the troposphere and lower stratosphere? For this purpose, the project was structured into three major subprojects. SP1, Engine exhaust emissions; SP2, Physics and chemistry in the aircraft wake; SP3, Global atmospheric model simulations. In addition, ANCAT, a European group of aviation experts, with support by the European Commission (EC), prepared an emissions data base for this project. The data flow is illustrated in Fig. 1. 


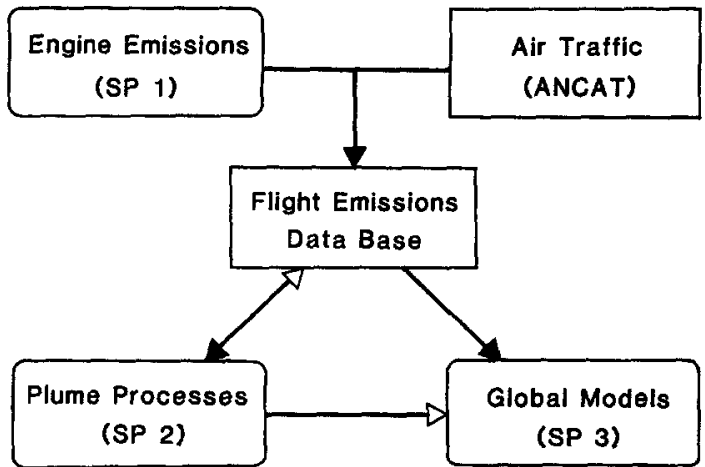

Fig. 1. Data flow within the AERONOX project and with the ANCAT/EC group.

The objectives of the individual subprojects were:

SP1: (a) to generate internationally acceptable reference data on aircraft engine emissions throughout the entire flight cycle up to $15 \mathrm{~km}$ altitude; (b) to make exploratory measurements of minor species to enable the evaluation of their contribution to plume chemistry. SP2: (a) to model the fluid dynamic and chemical kinetic processes in the jet and wake regimes; and (b) to understand the mechanisms of interaction. SP3: (a) to determine the three-dimensional (3D) $\mathrm{NO}_{x}$ concentration change due to aircraft; (b) to estimate the impact on the chemical composition (ozone, etc.); and (c) to determine the sensitivity to model differences. Finally, the objective of the ANCAT/EC working group was to collect civil air traffic data and estimates of military fuel consumption and to combine these data with aircraft performance and emissions estimates to produce a global emission data base for $\mathrm{NO}_{x}$ from air traffic in 1991/92.

The project lasted from August 1992 till October 1994 and included contributions from 16 partners from France, Germany, Great Britain, The Netherlands, Norway, and Sweden (see Schumann, 1995).

\section{METHODOLOGY}

The project made use of the following methods and research tools.

\subsection{Engine exhaust emissions (SP1)}

Semi-empirical functions predicting $\mathrm{NO}_{x}$ emissions: Such equations, usually called "correlations," predict $\mathrm{NO}_{x}$ emissions at flight conditions as a function of ambient temperature, pressure, humidity, speed of aircraft, engine parameters, fuel flow, and surface-based emission measurements. The equations approximate chemical kinetics based mainly on reaction temperature and residence time in the combustion zone.

Emissions measurements in altitude test chambers: Measurements were made of emissions from Rolls Royce RB211 and from Pratt and Wittney PW305 turbofan engines in altitude test-chambers at Pyestock and Stuttgart with full-scale engines, using standard emissions measurements technology. The high thrust RB211 engine is used on modern wide body aircraft. The smaller PW305 engine is used on long range, high altitude business jets. The test chambers can simulate the pressure, air speed and temperature which are typical of cruise conditions up to a height of about $15 \mathrm{~km}$ altitude.

Emissions measurements of these engines on combustor test rigs: Tests were run with variable inlet conditions, spanning more than the typical range of cruise conditions, both for the RB211 and PW 305 combustors. A combustor is that part of an engine in which part of the compressed air is mixed with fuel, where the combustion takes place, and where the resultant hot effluent is mixed with colder air to reduce the temperature to levels acceptable for the following turbo-fan engine section.

Trace species measurements: Gas probes were collected from the engine jets in test chambers and analysed in laboratory instruments to determine the contents of methane $\left(\mathrm{CH}_{4}\right)$, nitrous oxides $\left(\mathrm{N}_{2} \mathrm{O}\right)$, and some $\mathrm{NMHC}$ and carbonyl compounds (the sum of aldehydes and ketones).

\subsection{Physics and chemistry in the aircraft wake (SP2)}

Jet-flow models including thermodynamics and turbulence: Three models were used to compute and compare the jet flow from the engine exits up to a distance of about $30 \mathrm{~m}$ after the engines, using two-dimensional (2D) axisymmetric models and which include various forms of turbulence closure assumptions.

A $3 D$ computational jet-vortex fluid dynamics model: The dynamics of the aircraft-induced vortices, and jet mixing interaction was modelled with a newly developed code. The model started from initial condition representing a superposition of a simple vortex flow and the jet flow results after about $30 \mathrm{~m}$. The vortex model accounted for the induced trailing vortices from the wings. The model used structured grids of variable resolution and covered the exhaust plume up to about $1 \mathrm{~km}$ after the aircraft ( $4 \mathrm{~s}$ plume age). The model was applied mainly for a B767 aircraft with RB211 engines. A B747 aircraft with the same engines was also investigated.

Nucleation and particle growth model for contrail analysis: The models were based on temperature and humidity values along trajectories provided from the vortex model. The models followed a box along the trajectories mixing with the ambient air at a rate as given by the vortex model. Within the box, the model computed the growth of particles starting from a given aerosol spectrum. The model was applied for B767/RB211 conditions at relatively low ambient humidity.

Photochemical air chemistry gas-phase box model: The box model followed the same trajectories as the nucleation model, and computed the photochemistry of exhaust emissions. As an essential free parameter, the initial concentration of hydroxyl radicals $(\mathrm{OH})$ was varied parametrically.

Laboratory instruments for gas/soot interaction studies: Soot samples were placed in a heated reactor filled with NO gas. At both room temperature and high temperature (up to $1100 \mathrm{~K}$ ), the evolution of $\mathrm{NO}$ and the formation of other gases were monitored and soot samples were analysed.

A new large aerosol chamber for the study of nighttime chemistry (preliminarily applied without aerosols): At time scales of days, the interaction of $\mathrm{NO}_{2}$ with $\mathrm{O}_{3}$ at various water vapour $\left(\mathrm{H}_{2} \mathrm{O}\right)$ background levels in air was investigated for nighttime conditions at room temperatures, to determine relevant kinetics parameters.

\subsection{Global atmosphere model simulations ( $S P 3$ )}

A global $\mathrm{NO}_{x}$ emissions database was set up. Emissions data were collected for $\mathrm{NO}_{x}$ emission from aircraft, biomass burning, industry and surface traffic, microbial soil production, lightning, and stratospheric sources (Lee et al., 1996).

A hierarchy of models was provided. The models included 2D (latitude-height or longitude-height) and $3 \mathrm{D}$ and timedependent models, without chemistry for passive transport 
studies, with simplified (linear) chemistry for comparisons of various emissions, and with detailed (nonlinear) chemistry for ozone assessments. The models were based on either predefined meteorological conditions, analysed meteorological fields, or used self-computed meteorology with realistic climatology. Some models analysed the air chemistry along trajectories or for a large set of Lagrangian particles transported by observed $3 \mathrm{D}$ wind fields.

Four 2D chemistry models were used which treat either latitude-altitude or longitude-altitude cross-sections of the global atmosphere, with simple flow and mixing models, but extensive air chemistry models. The impact of the various model assumptions was determined by comparison of the different model results, using the same $\mathrm{NO}_{x}$ emissions scenario in each model. The longitude-altitude model allowed for analysis of zonal variations along a fixed northern zonal band covering the continents and ocean areas. The other models assumed zonal symmetry but allow for meridional exchange.

Four 3D chemical transport models were applied. The models used prescribed windfields, varying at different time and space scales and included parameterizations for subgrid-scale transport mechanisms. Moreover, the models described the photochemistry to various degrees. The models were used first to study the transport of $\mathrm{NO}_{x}$ as if it behaves as a passive tracer with a fixed exponential decay law. The decay half-times were varied between 4 and 20 days. These studies identified the importance of various transport processes for the resultant concentration fields. Thereafter, one of the models was applied with simplified chemistry, in which the $\mathrm{NO}_{x}$ concentration is a linear function of the emissions. The calculations quantified the relative contributions from various sources to the concentration level of the $\mathrm{NO}_{x}$ within the atmosphere. Finally, the models were applied with a more detailed nonlinear photochemistry in order to compute the impact of aviation $\mathrm{NO}_{x}$ emissions on ozone and other atmospheric constituents.

Two 3D atmospheric general circulation models were used. The models computed their own wind fields from the general dynamics of the atmosphere. Hence, these models will ultimately enable investigation of the feedback between chemistry and climate dynamics. Here, the models were used as chemical transport models for passive tracer and linear chemistry calculations. The results were compared with the other model results.

A trajectory/chemistry model was also used. Trajectories were computed following analysed $3 \mathrm{D}$ and time-dependent windfields, starting from various positions within the main flight corridors for a time period of about ten days. Thereafter, the chemistry was investigated for a box floating along the trajectories. The model allowed the concentration changes in air parcels to be related to the history of the air parcel.

\section{RESULTS}

In the following we list the major results and conclusions with respect to the various subprojects' objectives: For details we refer to Schumann (1995) and various publications which resulted from this project as cited below.

\subsection{Engine exhaust emissions ( $S P 1)$}

3.1.1. Data on aircraft engine emissions. Existing equations for prediction of $\mathrm{NO}_{x}$ emissions at cruise conditions were reviewed. The variability between the predictions of emissions at cruise was $\pm 18 \%$ for the nine equations considered, when they were referenced

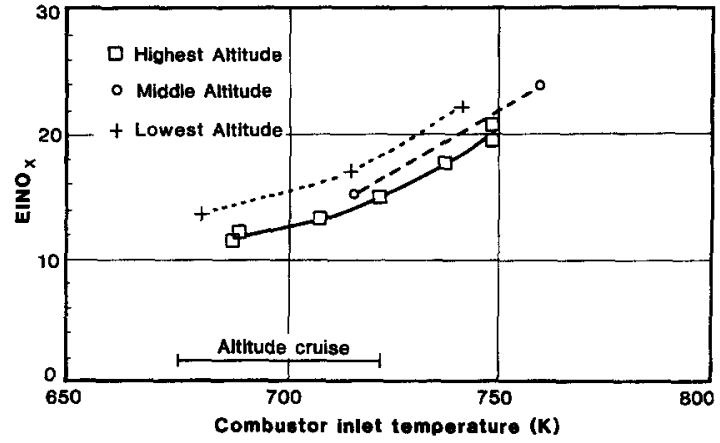

Fig. 2. Emission index of $\mathrm{NO}_{x}$ in $\mathrm{g}\left(\mathrm{NO}_{2}\right) \mathrm{kg}^{-1}$ vs combustor inlet temperature for the $\mathrm{RB} 211$ engine. The range of typical inlet temperatures at cruise altitude is indicated.

to ground-level certification $\mathrm{NO}_{x}$ emission data. The variability was much larger without such adjustments.

Engine emissions measurements were carried out on an RB211 and a PW305 engine over a range of conditions from sea level up to aircraft cruise altitude, using altitude test cells. For example, Figs 2 and 3 show the measured emission indices (EI, in $\mathbf{g}\left(\mathrm{NO}_{2}\right)$ per $\mathrm{kg}$ of fuel) vs the combustor inlet temperature at various altitudes. The emission index decreases with altitude and increases with inlet temperature. Typical EI values at cruise are between 11 and 14 for the RB211, and 6 and 10 for the PW305. The measurements indicated that virtually all $(98 \pm 2 \%)$ of the $\mathrm{NO}_{x}$ is emitted as NO. This appears to be typical for modern civil engines.

Emissions measurements were also made over a matrix of conditions of pressure, temperature, fuel and air mass flows using RB211 and PW305 combustors in test rigs. New prediction equations were derived from these data. These new $\mathrm{NO}_{x}$ equations were compared with the existing equations and some newer fuel-based prediction equations. These were found to be in good agreement. The prediction equations are sensitive to engine design variations between engine types or families. Nevertheless, for development of global inventories, the general application of an equation will give results having an uncertainty typically within $15-20 \%$, which is likely to be smaller than other sources of error. The $\mathrm{NO}_{x}$ emissions increase by about $12 \%$ when corrected with respect to environmental humidity from reference sea level values to actual atmospheric values at typical cruise altitudes.

3.1.2. Exploratory measurements of minor species. Initial surveys identified $\mathrm{OH}$ radicals, reactive nitrogen oxides $\left(\mathrm{NO}_{y}\right)$, sulphur compounds $\left(\mathrm{SO}_{x}\right)$, different hydrocarbons including carbonyl compounds, and soot particulates as the most important minor species to be studied in future projects. Some preliminary measurements of unregulated trace species $\left(\mathrm{N}_{2} \mathrm{O}\right.$, $\mathrm{CH}_{4}$, and carbonyls) were performed on the engines and combustors. For $\mathrm{N}_{2} \mathrm{O}$ and $\mathrm{CH}_{4}$, the results from the combustor test were comparable to the data from the engine tests. It was shown that air traffic does not 


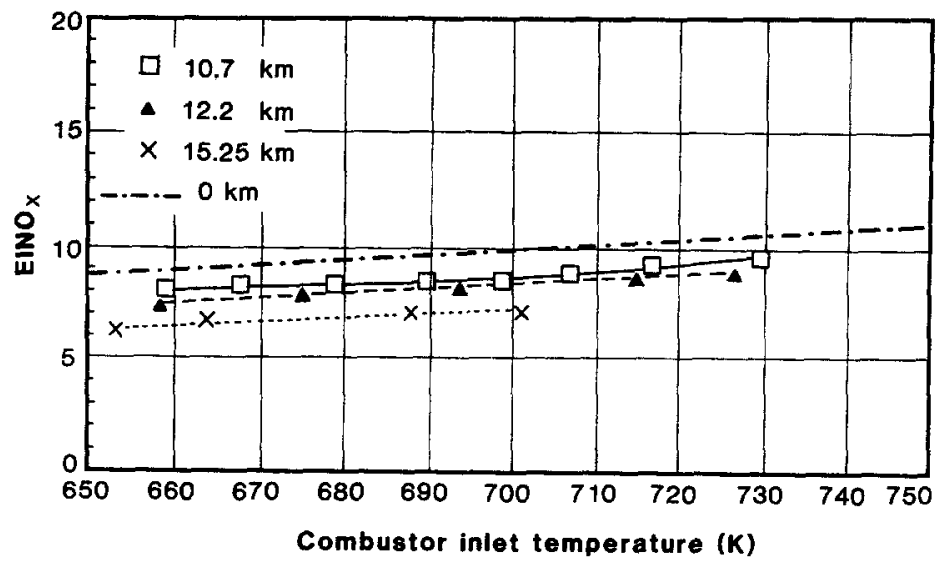

Fig. 3. Same as Fig. 2 for the PW 305 engine

contribute significantly to the global budget of $\mathrm{N}_{2} \mathrm{O}$ and $\mathrm{CH}_{4}$ (Wiesen et al., 1994). The emission index for $\mathrm{N}_{2} \mathrm{O}$ varied between 0.09 to $0.55 \mathrm{~g} \mathrm{~kg}^{-1}$ for the RB211, growing with thrust. The $\mathrm{CH}_{4}$ concentration in the exhaust is below ambient values for most conditions except at very low power settings. Measurements of carbonyl compounds showed lower levels on the combustor rig than the engine test. The emissions indices for carbonyls were not determined but the greatest emissions were obtained at the highest altitude.

The potential for making in-flight emissions measurements was studied. The use of conventional intrusive sampling techniques does not appear to be realistic. Other groups are preparing remote sensing methods (see reports in Schumann and Wurzel, 1994) or use in-situ measurements in the plumes some kilometers after the aircraft (Arnold et al., 1992; Schulte and Schlager, 1996). The insight gained in SP1 was used to specify the objectives for a follow-on program, aimed at the measurement of other important trace species from aeroengines.

In summary, altitude test chamber emissions measurements were made for cruise conditions for the first time on modern engines. Although limited to only two engines, the data base is very important in the validation of emission prediction equations. Cruise $\mathrm{NO}_{x}$ emissions from engines can now be estimated with a higher degree of reliability than before.

3.1.3. Emissions data base. In November 1992 the ANCAT group provided to SP3 an interim data base based upon the work by the Warren Spring Laboratory (WSL) (McInnes and Walker, 1992). This data base provided the $\mathrm{NO}_{x}$ emissions on a global 3D grid (altitude, latitude and longitude). It clearly showed that the highest $\mathrm{NO}_{x}$ emissions per grid volume occur over North America and Europe. A significant proportion of $\mathrm{NO}_{x}$ emissions was also found at cruise altitudes within the North Atlantic flight corridor.

In April 1994 ANCAT released the first version of its own database for aircraft $\mathrm{NO}_{x}$ emissions (available from DLR, FF-VL, Postfach 906058, D-51140 Köln, Germany). The data base is more detailed than the
WSL version, accounts for nearly all of the traffic, and is based upon new methodologies, most importantly the establishment of a movement data base which incorporates air traffic control records of actual flights for four selected months over a year to record seasonal variability (Gardner et al., 1996). About $92 \%$ of all $\mathrm{NO}_{x}$ emissions from aviation occur in the Northern Hemisphere, $40 \%$ of all are emitted over North America, 25\% over Europe, $10 \%$ over Asia, and $65 \%$ of all emissions are within the altitude range $11-13 \mathrm{~km}$. Calculated total $\mathrm{NO}_{x}$ mass is $2.78 \mathrm{Tg}\left(\mathrm{NO}_{2}\right) \mathrm{yr}^{-1}(1 \mathrm{Tg}=1 \mathrm{Mt})$ for a 12 month period (mid-1991 to mid-1992) and the fleet average $\mathrm{NO}_{x}$ emission index is $16.8 \mathrm{~g}\left(\mathrm{NO}_{2}\right)(\mathrm{kg} \text { fuel })^{-1}$, see Table 1. The values are larger than those of the comparable NASA emissions data set (Stolarski and Wesoky, 1993).

The WSL, NASA and ANCAT data bases provide the scientific community with the opportunity to assess the sensitivity of the atmosphere to varying amounts of aircraft emissions. The first version of the ANCAT inventory revealed a close agreement between calculated fuel consumption and published data on total refined jet fuel, as provided by IEA (1993), which was considered to be a suitable check for consistency, see Table 1. For modelling purposes, the three data bases were used alternatively within SP3 but all have been scaled to match the same total fuel consumption. This matching turned out to be problematic.

Under the auspices of the work programme of the ICAO environmental committee (CAEP) the data base produced by the ANCAT group has been compared with the NASA 1990 dataset (Stolarski and Wesoky, 1993). The obviously large differences triggered further investigations. Differences arise from two main sources: the movement data bases and the emission calculation methodologies. First, the data bases cover different time periods-the 2 yr gap will account for a difference in movement levels. Second, the ANCAT data base uses actual aircraft movements recorded by ATC where available which includes 
Table 1. Comparison of emission inventories

\begin{tabular}{|c|c|c|c|c|}
\hline & WSL & NASA & ANCAT & ANCAT revised \\
\hline Base year & 1989 & 1990 & 1991/92 & $1991 / 92$ \\
\hline Fuel, $\mathrm{Tg} \mathrm{yr}^{-1}$ & 85.6 & 126 & 165 & 130 \\
\hline Effective $\mathrm{EI}\left(\mathrm{NO}_{x}\right), \mathrm{g}\left(\mathrm{NO}_{2}\right)(\mathrm{kg} \text { fuel })^{-1}$ & 11.6 & 10.9 & 16.8 & 14.6 \\
\hline $\mathrm{NO}_{x}, \mathrm{Tg}\left(\mathrm{NO}_{2}\right) \mathrm{yr}^{-1}$ & 1.0 & 1.37 & 2.78 & 1.89 \\
\hline $\mathrm{NO}_{x}, \operatorname{Tg}(\mathrm{N}) \mathrm{yr}^{-1}$ & 0.30 & 0.42 & 0.85 & 0.57 \\
\hline Fuel match, \% & 51 & 76 & 99 & - \\
\hline Scaled $\mathrm{NO}_{x}, \mathrm{Tg}\left(\mathrm{NO}_{2}\right) \mathrm{yr}^{-1}$ & 1.9 & 1.9 & 2.8 & - \\
\hline Scaled $\mathrm{NO}_{x}, \operatorname{Tg}(\mathrm{N}) \mathrm{yr}^{-1}$ & 0.58 & 0.59 & 0.85 & - \\
\hline
\end{tabular}

Note: The fuel match is the fuel consumption covered by the emissions database divided by the global supply of aviation fuel of $166.34 \mathrm{Tg} \mathrm{yr}^{-1}$ reported by IEA (1993) for the year 1992 . The last two rows list the emissions scaled to $100 \%$ fuel match as used in the modelling projects within AERONOX. The revised ANCAT data are preliminary results provided by A. Schmitt, DLR (personal communication, June 1996).

many non-scheduled movements while the NASA data base is constructed using timetable data and a specific assessment of charter flights. The difference in approach will generally lead to more movements being recorded by ANCAT. Third the ANCAT data base includes significant doublecounting of movements within Europe (the NASA 1990 data base also contained a few double countings, Baughcum et al., 1996). A further difference is introduced through the emissions calculation methodology. NASA used a fuel-based approach drawing upon engine manufacturers' data whilst the ANCAT work is based upon a generic engine performance model which simulates engine operation conditions.

After completion of the present project, it was found that the aviation fuel values reported by IEA appear to overestimate the actual amount of fuel used by aircraft. The IEA figures cover jet fuel which satisfies the specification that allow its use in aircraft, but part of that fuel is used for ground vehicles, engine testing, and other uses (Thompson et al., 1996; Baughcum et al., 1996). Particularly in the winter, jet fuel is often purchased to mix with fuel oil to lower its freezing point since jet fuel has a low freezing point. In some years, monthly reports of refinery output show strong spikes in the winter that correspond more to the temperature than to any changes in air traffic (S. L. Baughcum and A. Momenthy, personal communication, 1996). Hence, there is no perfect data base with which to validate or evaluate the jet-fuel consumption data (Baughcum et al., 1996).

The ANCAT/EC group is in the process of producing a revised and improved data base using a fuelflow-based methodology and accounting for changes to the movement data base carried out in the light of validation work (Gardner et al., 1996). A preliminary result is included in Table 1. The NASA 1992 version gives slightly larger values than the first 1990 version, with fuel consumption and $\mathrm{NO}_{x}$-emissions of 134 and $1.46 \mathrm{Tg} \mathrm{yr}^{-1}$, respectively (Thompson et al., 1996, p. 24).

\subsection{Physics and chemistry in the aircraft wake (SP2)}

3.2.1. Fluid dynamic and chemical kinetic processes in the jet and wake regimes. Models were developed and applied for the jet and vortex phases. The codes computed (in two spatial dimensions and time or in three spatial dimensions) the flow, the thermodynamical fields, the concentrations of a tracer which characterizes the degree of mixing between the jet and the environment, and trajectories. The application has been limited to a $4 \mathrm{~s}$ time period, so that the conclusions are limited to the potential transformations occurring during the first $1 \mathrm{~km}$ behind the aircraft.

In the jet, large temperature fluctuations occur which may be important for particle formation processes. In the jet/vortex transition, after $4 \mathrm{~s}$, the jet is well mixed with the vortex, strongly diluted by environmental air, and most species are close to background levels except the $\mathrm{NO}_{x}$ family. The $\mathrm{OH}$ emission rate is essential for the formation of nitric acid $\left(\mathrm{HNO}_{3}\right)$, nitrous acid $\left(\mathrm{HNO}_{2}\right)$, sulphuric acid $\left(\mathrm{H}_{2} \mathrm{SO}_{4}\right)$, and dinitrogen pentoxide $\left(\mathrm{N}_{2} \mathrm{O}_{5}\right)$ formation during the jet phase and possibly for other species of the $\mathrm{NO}_{y}$ family which have not been taken into account in the chemical scheme. However, the computed reduction in $\mathrm{NO}_{x}$ levels due to formation of $\mathrm{HNO}_{3}$ remains small (less than $1 \%$ ) except at extremely large $\mathrm{OH}$ emission rates (Garnier et al., 1996).

Models were also developed for computing the ice formation and chemistry within a box travelling along trajectories. The condensation model started from soot with a typical size distribution and computed the size distribution and equivalent surface area for the ice crystals forming along the trajectory. The chemical box model also evaluated the evolution of hydroxy radicals $\left(\mathrm{HO}_{x}\right)$ in the wake. It was shown that the $\mathrm{OH}$ concentration is growing slowly during the vortex phase.

For undersaturated environmental humidities, the condensation of ice on soot particles is ephemeral and the heterogeneous $\mathrm{N}_{2} \mathrm{O}_{5}$ reaction with water has a negligible impact on the $\mathrm{HNO}_{3}$ production within the first $4 \mathrm{~s}$ of plume age. The precise form of the size spectrum of soot is unimportant under these conditions.

3.2.2. Mechanisms of interaction. Laboratory investigations were performed to determine parameters of gas/soot interactions and nighttime chemistry. The 
gas/soot interaction results in conversion of NO into $\mathrm{N}_{2}$ at high temperatures. However, the magnitude appears to have negligible effects for aircraft jets, because these reactions are important only at high temperature and long time scales which are not relevant for exhaust jets. The $\mathrm{HNO}_{3}$ solution interaction with soot, at room temperature, results in nonnegligible conversion into $\mathrm{N}_{2} \mathrm{O}$, but the rate is too slow to affect the concentrations over the limited $4 \mathrm{~s}$ period. For nighttime chemistry, revised reaction coefficients were determined.

In summary, the amount of $\mathrm{NO}_{x}$ in the plume remains essentially at a constant level from the engine exit to $1 \mathrm{~km}$, at least under the conditions studied. The processes are, however, very complex and the behaviour of aged plumes beyond $4 \mathrm{~s}$ and persistent contrails have not yet been investigated. Based on this $4 \mathrm{~s}$ of simulation, the conclusion from SP2 suggests that the original emissions data base from SP1 can be used for SP3 calculations.

\subsection{Global atmosphere model simulations (SP3)}

3.3.1. The $3 D \mathrm{NO}_{x}$ concentration change due to aircraft. Considerable progress was made in modelling the physical and chemical properties of the upper troposphere and lower stratosphere. A hierarchy of models was provided or specially developed to investigate the impact of the $\mathrm{NO}_{x}$ emissions from aviation on the chemical state of the atmosphere, based on the emissions data bases of ANCAT, NASA, and the preliminary data base of WSL. The models include both 2D and 3D representations of the atmosphere, without chemistry for passive transport studies, with simplified (linear) chemistry for comparisons of various $\mathrm{NO}_{x}$ emissions, and with more detailed (nonlinear) chemistry for ozone assessments (e.g. Collins et al. 1996).

Because of the $3 \mathrm{D}$ emission pattern and a residence time shorter than the zonal mixing time, the $\mathrm{NO}_{x}$ increase due to aviation emission deviates strongly from a zonal 2D mean field and shows high temporal variability (Sausen and Köhler, 1994; Velders et al., 1994; Wauben et al., 1996; van Velthoven et al., 1996). The $\mathrm{NO}_{x}$ emitted into the corridors is transported mainly eastward and downward. There are strong differences between winter and summer conditions. Interhemispheric transport of aircraft emissions is small. The $\mathrm{NO}_{x}$ concentration increase due to aircraft is at a maximum at cruise altitudes.

Although many of the sources and transport paths of $\mathrm{NO}_{x}$ are uncertain, it was shown that aviation contributes a large fraction to the total concentration of $\mathrm{NO}_{x}$ in the upper troposphere, in particular north of $30 \mathrm{~N}$; see Table 2. In January, aircraft are responsible for most of the $\mathrm{NO}_{x}$ concentration to be found in the Northern hemisphere extra-tropics at cruise altitudes (Köhler et al., 1996).

3.3.2. The impact on the chemical composition. Because of the longer lifetime of ozone, the change in ozone from aircraft $\mathrm{NO}_{x}$ emissions is much more
Table 2. The contribution of individual nitrogen oxide soures to the atmospheric burden of nitrogen oxides at the region $30-60^{\circ} \mathrm{N}$ and $200-300 \mathrm{hPa}$, based on runs with the global circulation model ECHAM (Köhler et al., 1996) and the GISS-chemical transport model (Kraus et al.. 1996) with linear chemistry

\begin{tabular}{lcc}
\hline & January & July \\
\hline Surface sources & $23-28 \%$ & $54-57 \%$ \\
Lightning & $2-5 \%$ & $15 \% 17 \%$ \\
Stratospheric sources & $<35 \%$ & $1-7 \%$ \\
Aircraft emissions & $40-67 \%$ & $20.25 \%$ \\
\hline
\end{tabular}

Table 3. Calculated maximum relative changes of zonal mean values of various air constituents at northern midlatitudes near $200 \mathrm{hPa}$ due to aircraft emissions. in 1989 , based on the chemical transport model CTMK (Wauben et al., 1996)

\begin{tabular}{lcc}
\hline Constituent & January & July \\
\hline $\mathrm{NO}_{x}$ & $53 \%$ & $34 \%$ \\
$\mathrm{O}_{3}$ & $4 \%$ & $9 \%$ \\
$\mathrm{HNO}_{3}$ & $28 \%$ & $32 \%$ \\
$\mathrm{OH}$ & $32 \%$ & $18 \%$ \\
\hline
\end{tabular}

zonally symmetric than the $\mathrm{NO}_{x}$ concentration. However, the $\mathrm{NO}_{x}$ emissions also influence the zonal variations due to the diurnal solar cycle of some of the short-lived species, e.g. OH. Aviation $\mathrm{NO}_{x}$ generally causes increases in tropospheric ozone. The maximal zonal mean $\mathrm{O}_{3}$ change is found in the Northern hemisphere at latitudes of the main flight corridors with increases of up to $10 \%$ of the concentration which is calculated without aircraft emissions; see Table 3. Some of the results are presented and discussed in further detail in Kraus et al. (1996), Stevenson et al. (1996), and Wauben et al. (1996).

The efficiency by which $\mathrm{NO}_{x}$ causes ozone production due to photochemical reactions with background $\mathrm{CO}, \mathrm{CH}_{4}$, and other hydrocarbons is highest for low $\mathrm{NO}_{x}$ concentrations but smaller in more polluted air. Therefore, the ozone production rate per unit of additional $\mathrm{NO}_{x}$ is largest in areas remote from the continents and the tropics and remote from the major air traffic corridors. Typically, the ozone production per molecule of $\mathrm{NO}_{x}$ ranges between 1 and 40 . Sensitivity studies show a maximum in the ozone production rate as a function of the $\mathrm{NO}_{x}$ concentration. In some highly polluted areas, e.g. over the North American continent or over Europe, the $\mathrm{NO}_{x}$ concentration is already so high that additionally released $\mathrm{NO}_{x}$ reduces the effective $\mathrm{O}_{3}$ production rate (Ehhalt and Rohrer, 1995). The exact $\mathrm{NO}_{x}$ level at which the $\mathrm{O}_{3}$ production rate achieves its maximum is rather model dependent (see also Flatoy and Hov, 1996; Brasseur ef al., 1996). Further studies are required to understand fully the consequences of these nonlinearities. Despite this complication, all of the models simulated similar 
ozone increases due to aircraft $\mathrm{NO}_{x}$ emissions, even in regions with a high background concentration.

Except for one model which computes small ozone changes in the lower tropical stratosphere, the models show no reduction in lower stratospheric ozone from the emissions of the subsonic traffic.

3.3.3. Sensitivity to model differences. With respect to $\mathrm{NO}_{x}$ concentration increase, the results of the various models which were used show a rather good agreement, though detailed differences may be noted. In particular, the passive tracer experiments, which were performed with identical experimental designs, gave similar results with respect to interhemispheric exchange and transport into the stratosphere (except for models with a coarse vertical resolution). Differences were found in the meridional transport (to the North Pole) by the transient parts of the circulation, e.g. by cyclones.

The results obtained with simplified chemistry are also similar. Differences mainly result from different dynamics of the two models. Large differences are found with respect to the simulated ozone change. Here the results only show a qualitative agreement and further investigations are needed to understand the differences. The model output strongly depends on the approximations used for the nonlinear chemistry. Differences also arise from internal variability. In particular for 3D models with rather sophisticated chemistry, the simulation time was too short. Within the current project the reasons for these differences could not all be quantified, and this open question has to be postponed to a follow-up project.

3.3.4. Remarks. At the conclusion of the project, it has to be kept in mind that all the models are still far from being fully validated by comparison to observations. In particular, the emission values of SP1 should be tested by independent means, possibly by inflight measurements. The jet and vortex results of SP2 need to be extended to a much wider range of atmospheric and aircraft conditions and should be compared in more detail with observational data. Also the global model predictions of photochemical changes and ozone formation within SP3 have not yet been compared to observed trace gas distributions in detail, in particular to those of $\mathrm{NO}_{x}$ and ozone, and their trends. In general, there are insufficient observations to permit adequate model validation. Recently, available data have been compiled into a first version of climatologies of tropospheric $\mathrm{NO}_{x}$ and $\mathrm{NO}_{y}$ and applied to test global chemical transport models (Emmons et al., 1996).

With respect to conclusions for general environmental policy, the limitations in the scope of the AERONOX project objectives, the amount of work performed, and the stated uncertainties in the results have to be taken into account. The project did not address all emissions nor all consequences of the induced changes. In particular, the project did not investigate the effects of contrail formation, which may have a climatological effect of the same order as the induced ozone changes (Ponater et al., 1996). Besides water and $\mathrm{CO}_{2}$, the $\mathrm{NO}_{x}$ emissions appear to be the most important emission species to be considered, whereas other emissions (such as carbon monoxide and hydrocarbons) are of only secondary importance. The effect of sulphur, soot and other particle emissions on aerosol and cloud formation and atmospheric chemistry is yet largely unknown. More emphasis has to be put on investigating the impact of chemical conversion of emissions at scales between the vortex regime and the global scale. There are indications from model calculations (see e.g. Sections 6 and 7 in Schumann and Wurzel, 1994), but no observational evidence, that these changes can be substantial enough to generate long-lived reservoir gases that significantly change the impact of $\mathrm{NO}_{x}$ emissions on the global photochemistry. Future projects still have to determine the climatological changes caused by aircraft emissions compared to changes by other climatic disturbances, both natural and anthropogenic. It is expected that the aviation effects are larger than measured in terms of the carbon dioxide emissions but still small in comparison to many other climate disturbances, at least at the present level of emissions. The long-term trends are such that this topic will remain highly relevant in the future. With respect to emissions inventories, it would be helpful if the aviation industry would monitor and publish the actual fuel consumption, data on fuel composition (e.g. with respect to sulphur), emission relevant properties of the engines used, and flight conditions (such as altitude, engine parameters, etc.) of the aviation fleets.

\section{CONCLUSIONS}

The amount of aircraft emissions throughout the entire flight cycles up to $15 \mathrm{~km}$ altitude has been determined mainly with respect to $\mathrm{NO}_{x}$ emissions, resulting in a total of $0.85 \mathrm{Tg}(\mathrm{N}) \mathrm{yr}^{-1}$ and an average emission index of $16.8 \mathrm{~g}\left(\mathrm{NO}_{2}\right) \mathrm{kg}^{-1}$ for $1991 / 92$. After completion of the AERONOX project, the ANCAT group reevaluated the data resulting in slightly smaller values: $0.57 \mathrm{Tg}(\mathrm{N}) \mathrm{yr}^{-1}$ total $\mathrm{NO}_{x}$ emissions with an average emission index of $15.3 \mathrm{~g}\left(\mathrm{NO}_{2}\right) \mathrm{kg}^{-1}$. These values are still slightly larger than the values provided by the NASA emission database for 1990. The chemical composition in the wake of the aircraft has been determined up to about $1 \mathrm{~km}$ behind one aircraft. The $\mathrm{NO}_{x}$ emissions remain essentially unchanged up to that distance. The later dispersion phase has not been investigated. The $\mathrm{NO}_{x}$ distribution from aircraft on the global scale was computed with 3D models. During winter months, aircraft are the dominant source for $\mathrm{NO}_{x}$ found at around $200 \mathrm{hPa}$ in the Northern hemisphere mid-latitudes. In summer, because of stronger upward transport and lightning sources, the relative contribution from aviation is smaller. The $\mathrm{NO}_{x}$ emissions by air- 
craft cause an increase in the tropospheric and lower stratospheric ozone concentrations by a few percent on average, with a maximum in the summer months. Locally, the 3D ozone concentration changes at global model grid scales show increases of up to $10 \%$. This result is very sensitive to the background values of nitrogen oxides, and to details of the models.

The results obtained in this study corroborate previous predictions that aviation is a major contributor to $\mathrm{NO}_{x}$ disturbances of the atmosphere. It is confirmed that, on average, $\mathrm{NO}_{x}$ emissions from subsonic aviation cause ozone increases. The impact per unit $\mathrm{NO}_{x}$ emission of these disturbances on ozone is strongest in relatively clean air. A doubling of aviation emissions in the northern hemisphere will cause less than a doubling of present aviation's contribution to tropospheric ozone increase.

Several questions remain open with respect to emissions, transport and chemistry, climate, and validation:

Emissions: (1) How reliable are the emissions inventories and what are the emissions inventories for other trace substances, in particular $\mathrm{H}_{2} \mathrm{O}, \mathrm{S}, \mathrm{HCs}$, and soot? What are the daily and seasonal cycles, what was the emission trend in the past (e.g. since 1982 or even earlier) and how will it develop in the future (say up to 2015 or 2050)? (2) What are the emission rates for $\mathrm{NO}_{x}$ from other sources than aviation, in particular from lightning? (3) Are the current prediction methods valid for aeroengines incorporating radically different combustors, e.g. double annular, axially staged, lean premixed-prevaporised, and rich burnquick mix-lean-burn concepts (Joos and Pellischek, 1995)?

Transport and chemistry: (1) Can one confirm that the $\mathrm{NO}_{x}$ conversion due to chemical reactions in the early jet/vortex regime is negligible? (2) What are the effects of emission conversions in the plume from the end of the vortex regime up to scales resolvable by global models and how can this be modelled? (3) What are the background concentrations for $\mathrm{NO}_{x}$, $\mathrm{OH}$, and ozone in the mid- and upper troposphere and lower stratosphere? (4) What are the detailed transport mechanisms for surface emissions and for stratospheric sources towards the tropopause region? (5) Can it be confirmed that the emissions from subsonic aviation do not get transported in any significant quantity to the mid-stratosphere with its ozone maximum and do not cause any essential ozone reductions there? (6) What is the impact of a hypothetical future supersonic transport system? (7) What is the spatial distribution of changes in radiatively active gases (mainly ozone, but also methane and others) and particles caused by aviation for the present situation and in the future?

Climate: (1) How and how often do contrails form and what are their effects on plume chemistry? (2) How do changes in atmospheric chemistry affect radiation (UV, visible and infrared) and climate? (3) How do contrails affect radiation and climate? (4) What feedbacks are to be expected from changes in climate to air chemistry and vice versa?

Validation: (1) Can one verify the transport and chemistry of the emitted quantities at various scales from jet exit to global scale, in special cases and climatologically? (2) How reliable are the computed changes in air chemistry due to aviation? Can this be validated by comparison to observed concentration fields (e.g. Emmons et al., 1996) and their decadal trends? (3) Are the climate models sufficiently adequate for such coupled studies, e.g. with respect to those parameters which affect chemistry of shortlived compounds, such as temperature, humidity, transport, washout, dry deposition, photolysis, etc.?

Most of these problems are of a complexity which require major research efforts. Several follow-on projects were initiated from the results of AERONOX.

Acknowledgements--The AERONOX project was performed under CEC Contract EV5V-CT91-0044 with financial support by the Commission of the European Communities, within the Research and Development Environment Programme 1991-1994, and under guidance of $G$. Angeletti and R. Dunker of DG XII-D1 and C3. Additional support has been provided by the partners and by national agencies. The AERONOX subprojects were coordinated by D. Lister, N. Louisnard, and R. Sausen. The ANCAT emission inventory was set-up under the guidance of R. Gardner. The project administrator was W. Dewes. Several colleagues and reviewers helped to improve this overview. The author expresses his gratitude to all of them.

\section{REFERENCES}

ANAE (1994) Space, Aeronautics and Atmospheric Effects. Int. Colloq., Toulouse, 15-17 March 1994. Academie Nationale de l'Air et de l'Espace, Association Aeronautique et Astronautique de France. Cepadues-Ed., 111, rue Nicolas-Vauquelin, 31100 Toulouse, France, p. 446.

Arnold F., Scheidt J., Stilp T., Schlager H. and Reinhardt M. E. (1992) Measurements of jet aircraft emissions at cruise altitude I: the odd-nitrogen gases $\mathrm{NO}, \mathrm{NO}_{2}$ $\mathrm{HNO}_{2}$, and and $\mathrm{HNO}_{3}$ Geophys. Res. Lett. 19, 2421 2424.

Baughcum S. L., Tritz T. G., Henderson S. C. and Picket D. C. (1996) Scheduled civil aircraft emission inventories for 1992: database development and analysis. NASA Contractor Report 4700, NASA Langley Res. Center. Hampton, Virginia 23681-0001.

Beck J. P., Reeves C. E., de Leeuw F. A. A. M. and Penkett S. A. (1992) The effect of air traffic emissions on tropospheric ozone in the northern hemisphere. Atmospheric Environment 26A, 17-29.

Brasseur G. P., Müller, J.-F. and Granier C. (1996) Atmospheric impact of $\mathrm{NO}_{x}$ emissions by subsonic aircraft: a three-dimensional model study. J. geophys. Res. 101, $1423-1428$.

Brühl C. and Crutzen P. J. (1988) Scenarios of possible changes in atmospheric temperatures and ozone concentrations due to man's activities, estimated with a onedimensional coupled photochemical climate model. Clim. Dyn. 2, 173-203.

CIAP (1975) Climatic impact assessment program, US Department of Transportation Final Report. DOT-TST. 75-51 and ff. (8 vols.) 
Collins W. J., Stevenson D. S., Johnson C. E. and Derwent R. G. (1996) Tropospheric ozone in a global-scale threedimensional Lagrangian model and its response to $\mathrm{NO}_{x}$ emission controls. J. atmos. Chem. (submitted)

COMESA (1976) The Report of the Committee on Meteorological Effects of Stratospheric Aircraft. Parts 1 and 2, United Kingdom Meteorological Office, Bracknell.

COVOS (1976) Activités 1972-1976. Comité d'études sur les conséquences des vols stratosphériques, Boulogne, France.

Crutzen P. J. (1971) Ozone production rate in an oxygenhydrogen-nitrogen oxide atmosphere. J. geophys. Res. 76, 7311-7327.

Crutzen P. J. (1972) SST's-a threat to the earth's ozone shield. Ambio 41-51.

Deutscher Bundestag (ed.) (1994) Mobilität und Klima. Wege $z u$ einer klimaverträglichen Verkehrspolitik. EnqueteKommission "Schutz der Erdatmosphäre., des Deutschen Bundestages, p. 390. Economia Verlag, Bonn.

EAC (1995) Seventh European Aerospace Conference, The Supersonic Transport of Second Generation. 25-28 October 1994, Toulouse, AAAF, 6 rue Galilée, 75782 Paris.

Ehhalt D. H. and Rohrer F. (1995) The impact of commercial aircraft on tropospheric ozone. In The Chemistry of the Atmosphere-Oxidants and Oxidation in the Earth's Atmosphere. 7th BOC Priestley Conf., Lewisburg, Pennsylvania, 1994 (edited by Brandy A. R.), pp. 105-120. The Royal Society of Chemistry, Special Publication No. 170.

Ehhalt D. H., Rohrer F. and Wahner A. (1992) Sources and distribution of $\mathrm{NO}_{x}$ in the upper troposphere at northern mid-latitudes. J. geophys. Res. 97, 3725-3738.

Emmons L. K. et al. (1997) Climatologies of $\mathrm{NO}_{x}$ and $\mathrm{NO}_{y}$ : a comparison of data and models. Atmospheric Environment 31, 1851-1904.

Fehsenfeld F. C. and Liu S. C. (1994) Tropospheric ozone: distribution and sources. In Global Atmospheric Chemical Change (edited by Hewitt C. N. and Sturges W. T.), Chap. 5, pp. 169-231. Elsevier, London.

Flatoy $F$. and Hov $\emptyset$ (1996) Three-dimensional model studies of the effect of $\mathrm{NO}_{x}$ emissions from aircraft on ozone in the upper troposphere over Europe and the North Atlantic. J. geophys. Res. 101, 1401-1422.

Fortuin J. P. F., van Dorland R., Wauben W. M. F. and Kelder H. (1995) Greenhouse effects of aircraft emissions as calculated by a radiative transfer model. Ann. Geophys. 13, 413-418.

Gardner R. et al. (1997) The ANCAT/EC global inventory of $\mathrm{NO}_{x}$ emissions from aircraft. Atmospheric Environment 31, 1751-1766.

Garnier F., Baudoin C., Woods P. and Louisnard N. (1997) Engine emission alteration in the near field of an aircraft. Atmospheric Environment 31, 1767-1781.

Harrison H. (1970) Stratospheric ozone with added water vapor: influence of high-altitude aircraft. Science. 170, 734-736.

Held M. (1990) Ecological Impacts of Aircraft Emissions, p. 59. Tutzinger Materialie No. 66, Ev. Akad. Tutzing, Postfach 227, 82327 Tutzing, ISSN 0930-7850.

Hoinka K. P., Reinhardt M. E. and Metz W. (1993) North Atlantic air traffic within the lower stratosphere: cruising times and corresponding emissions. J. geophys. Res. 98, 23,113-23,131.

IEA (1993) Oil and Gas Information 1992. International Energy Agency, OECD, Paris, France, ISBN 92-64-03872-8.

Johnson C., Henshaw J. and McInnes G. (1992) Impact of aircraft and surface emissions of nitrogen oxides on tropospheric ozone and global warming Nature 355, 69-71.

Johnston H. S. (1971) Reduction of stratospheric ozone by nitrogen oxide catalysts from supersonic transport exhaust. Science 173, 517-522.
Joos F. and Pellischek G. (1995) Low emissions combuster technology (LOWNOX 1). In Advances in Engine Technology (edited by Dunker R.), pp. 105-152. Wiley, Chichester.

Köhler I., Sausen R. and Reinberger R. (1997) Contributions of aircraft emissions to the atmospheric $\mathrm{NO}_{x}$ content. Atmospheric Environment 31, 1801-1808.

Kraus A. B., Rohrer F., Grobler E. S. and Ehhalt D. H. (1996) The global tropospheric distribution of $\mathrm{NO}_{x}$ estimated by a 3-D chemical tracer model. J. geophys. Res. 101, $18587-18604$.

Lee D. S., Köhler I., Grobler E., Rohrer F., Sausen R., Gallardo Klemer L., Olivier J. J. G. and Dentener F. J. (1997) Estimates of global $\mathrm{NO}_{x}$ emissions from non-aviation sources. Atmospheric Environment 31, $1735-1749$.

Logan J. A. (1994) Trends in the vertical distribution of ozone: an analysis of ozonesonde data. J. geophys. Res. 99, 25,553-25,585.

McInnes G. and Walker C. T. (1992) The global distribution of aircraft air pollution emissions. Warren Spring Lab., Report No. LR 872 (AP).

Mohnen V. A., Goldstein W. and Wang W.-C. (1993) Tropospheric ozone and climate change. Air Waste. 43, 1332-1344.

NRC (1994) Atmospheric Effects of Stratospheric Aircraft. An evaluation of NASA's Interim Assessment. p. 45. National Research Council. National Academy Press, Washington, District of Columbia

Ponater M., Brinkop S., Sausen R. and Schumann U. (1996) Simulating the global atmospheric response to aircraft water vapour emissions and contrails-a first approach using a GCM. Ann. Geophys. 14, 941-960.

Sausen R. and Köhler I. (1994) Simulating the global transport of nitrogen oxides from aircraft. Ann. Geophys. 12, 394-402.

Schulte P. and Schlager H. (1996) In-flight measurements of cruise altitude nitric oxide emission indices of commercial jet aircraft. Geophys. Res. Lett. 23, 165-168.

Schumann U. (ed.) (1990) Air Traffic and the EnvironmentBackground, Tendencies and Potential Global Atmospheric Effects. Proc. DLR Int. Coll., Bonn, 15/16, Nov. 1990, Lecture Notes in Engng, Vol. 60, p. 170. Springer, Berlin.

Schumann U. (1994) On the effect of emissions from aircraft engines on the state of the atmosphere. Ann. Geophys. 12, 365-384.

Schumann U. (ed.) (1995) AERONOX--The Impact of $\mathrm{NO}_{x}$ Emissions from Aircraft upon the Atmosphere at Flight Altitudes 8-15 km, p. 471. Publication EUR 16209 EN, ISBN-92-826-8281-1, Office for Publications of the European Commission, Brussels

Schumann U. and Wurzel D. (eds) (1994) Impact of Emissions from Aircraft and Spacecraft upon the Atmosphere. Proc. Int. Sci. Coll., Köln (Cologne), Germany, 18-20 April, p. 496, DLR-Mitt. 94-06.

Stevenson D. S., Collins W. J., Johnson C. E. and Derwent R. G. (1997) The impact of aircraft nitrogen oxide emissions on tropospheric ozone studied with a 3-D Lagrangian model including fully diurnal chemistry. Atmospheric Environment 31, 1837-1850.

Stolarski R. S. and Wesoky H. L. (eds) (1993) The Atmospheric Effects of Stratospheric Aircraft: $A$ Third Program Report, p. 413. NASA Reference Publication 1313, NASA, Washington, District of Columbia.

Thompson A. M., Friedl R. R. and Wesoky H. L. (eds) (1996) The Atmospheric Effects of Aviation: First Report of the Subsonic. p. 413. NASA Reference Publication 1385, NASA, Washington, District of Columbia.

van Velthoven P. F. J., Wauben W. M. F., Kelder H., Köhler I., Sausen R., Rohrer F, and Kraus A. B. (1997) Passive transport studies. Atmospheric Environment 31, 1783-1799. 
Velders G. J. M., Heijboer L. C. and Kelder H. (1994) The simulation of the transport of aircraft emissions by a three-dimensional global model. Ann Geophys. 12, 385-393.

Wauben W. M. F., van Velthoven P. F. J. and Kelder H. (1997) A 3d chemical transport model study of changes in atmospheric ozone due to aircraft emissions. Atmospheric Environment 31, 1819-1836.
Wiesen P., Kleffmann J., Kurtenbach R. and Becker K. H (1994) Nitrous oxide and methane emissions from aero engines. Geophys. Res. Lett. 21, 2027-2030.

WMO (1995) Scientific Assessment of Ozone Depletion: 1994 Chap. 11, pp. 11.1-11.32. World Meteorological Organization, Global Ozone Research and Monitoring ProjectReport No. 37, Geneva. 